\title{
Blocking of progestin action disrupts spermatogenesis in Nile tilapia (Oreochromis niloticus)
}

\author{
Gang Liu, Feng Luo, Qiang Song, Limin Wu, Yongxiu Qiu, Hongjuan Shi, Deshou Wang \\ and Linyan Zhou
}

Key Laboratory of Freshwater Fish Reproduction and Development (Ministry of Education), Key Laboratory of Aquatic Science of Chongqing, School of Life Science, Southwest University, Chongqing 400715, People's Republic of China
Correspondence should be addressed to L Zhou or D Wang Emails yanlinzhou916@126.com or wdeshou@swu.edu.cn

\begin{abstract}
In vitro studies have indicated that the maturation-inducing hormone $17 \alpha, 20 \beta$-dihydroxy-

4-pregnen-3-one (17 $\alpha, 20 \beta-D P, D H P)$, probably through nuclear progestin receptor (Pgr), might be involved in the proliferation of spermatogonial cells and the initiation of meiosis in several fish species. However, further in vivo evidence is required to elucidate the role of DHP in spermatogenesis during sexual differentiation in teleosts. In this study, we cloned pgr and analyzed its expression in Nile tilapia (Oreochromis niloticus) and treated XY fish with RU486 (a synthetic Pgr antagonist) from 5 days after hatching (dah) to determine the role of DHP in spermatogenesis. Sequence and phylogenetic analyses revealed that the Pgr identified in tilapia is a genuine Pgr. Pgr was found to be expressed in the Sertoli cells surrounding spermatogonia and spermatids in the testis of tilapia. Real-time PCR analysis revealed that the expression of pgr in the testis was significantly upregulated from $10 \mathrm{dah}$, further increased at 50 dah, and persisted until adulthood in fish. In the testis of RU486-treated fish, the transcript levels of germ cell markers and a meiotic marker were substantially reduced. However, the expression of markers in Sertoli cells remained unchanged. Moreover, the production of 11-ketotestosterone and the expression of genes encoding various steroidogenic enzymes were also not altered. In contrast, the expression of cyp17a2, encoding one of the critical steroidogenic enzymes involved in DHP biosynthesis, declined significantly, possibly indicating the inhibition of DHP production by RU486. RU486 treatment given for 2 months did not affect spermatogenesis; however, treatment given for more than 3 months resulted in a decrease in spermatogonial cell numbers and depletion of later-phase spermatogenic cells. Simultaneous excessive DHP supplementation restored spermatogenesis in RU486-treated XY fish. Taken together, our data further indicated that DHP, possibly through Pgr, might be essential for spermatogonial cell proliferation and spermatogenesis in fish.
\end{abstract}

Key Words

- DHP

- Pgr

- RU486 treatment

- spermatogenesis

Journal of Molecular Endocrinology (2014) 53, 57-70

\section{Introduction}

In teleosts, two major biologically active progestins, $17 \alpha, 20 \beta$-dihydroxy-4-pregnen-3-one (17 $\alpha, 20 \beta$-DP, DHP) and 17,20 3,21 -trihydroxy-4-pregnen-3-one, have been identified and proved to be essential for spermatogenesis (Schulz et al. 2010, Scott et al. 2010). It is well documented that DHP plays crucial roles in final sperm maturation, http://jme.endocrinology-journals.org DOI: 10.1530/JME-13-0300
(C) 2014 Society for Endocrinology Printed in Great Britain
Published by Bioscientifica Ltd 
spermiation (Ueda et al. 1985), and sperm motility enhancement in mature fish (Miura et al. 1992, Tubbs \& Thomas 2008). However, it has been shown that DHP is produced by both mature and immature testes at different stages, indicating its diverse roles before and during spermatogenesis in rainbow trout (Oncorhynchus mykiss; Depeche \& Sire 1982). Recent reports have revealed that DHP might play critical roles in the initiation of meiosis in Japanese eel (Anguilla japonica) (Miura et al. 2006) and in the early stages of spermatogenesis in Atlantic salmon (Salmon salar), cod (Gadus morhua), and zebrafish (Danio rerio) (Chen et al. 2010, 2011, 2012, 2013). Furthermore, it has been proven in in vitro experiments that DHP can induce the conversion of $11 \beta$-hydroxytestosterone to 11-ketotestosterone (11-KT, the main androgen in fish) by stimulating the activity of 11ß-hydroxysteroid dehydrogenase (encoded by cyp11b2) in Japanese eel and zebrafish (Ozaki et al. 2006, Chen et al. 2010). In contrast, it has been shown in adult zebrafish that $17 \beta$-estradiol $\left(\mathrm{E}_{2}\right)$-mediated suppression of spermatogenesis could be successfully restored by DHP treatment without increasing 11-KT production (Chen et al. 2013). Therefore, there might be clear discrepancies between in vitro and in vivo assays in fish as to whether DHP-regulated spermatogenesis depends on 11-KT production.

The functions of progesterone are mainly mediated by nuclear progesterone receptor. RU486, an orally active compound for absorption used in FDA-approved medical treatment, binds to the progesterone receptor with twofold higher affinity than progesterone (Heikinheimo et al. 2003). So far, nuclear progestin receptors have been identified and characterized in several fish species, with variable expression profiles being detected in Sertoli cells, Leydig cells, and germ cells (Chen et al. 2010, 2011, 2012, Hanna et al. 2010). An in vitro assay carried out using mammalian cell culture has proved that a functional progestin receptor (Pgr) can transactivate target genes in a DHP-dependent manner, supporting the view that DHP is the major native ligand of nuclear Pgr in fish (Chen et al. 2010). Using a testicular incubation system, Chen et al. (2010) also demonstrated that DHP stimulates the production of 11-KT in a Pgr-dependent manner, while RU486 (a synthetic Pgr antagonist) could inhibit its action by suppressing Pgr-mediated transactivation. Therefore, it has been proposed that Pgr might mediate the actions of DHP in spermatogonial cell proliferation, meiosis initiation, and spermatogenesis in fish. However, further in vivo investigations are needed to determine the role of DHP in spermatogenesis, possibly via Pgr, in fish.
Tilapia is an economically important species for aquaculture and also an ideal model for studying fish gametogenesis because of the availability of monosex larvae and well-studied functions of DHP during gamete maturation (Senthilkumaran et al. 2002, Zhou et al. 2007). However, the role of DHP in spermatogenesis during sexual differentiation remains largely unknown. To further elucidate the possible roles and mechanisms of Pgr-mediated actions of DHP in spermatogonial cell proliferation and spermatogenesis in tilapia, in this study, pgr was identified and its expression profile was analyzed at different stages of gonadal differentiation in tilapia. Furthermore, XY fry were treated with a Pgr antagonist (RU486) from 5 days after hatching (dah), the critical sex determination period of tilapia, for 2,3 , or 5 months. Finally, DHP and 11-KT were used to rescue the RU486-disrupted spermatogenesis.

\section{Materials and methods}

\section{Fish}

Tilapia were reared in large tanks with a re-circulating aerated freshwater system at ambient temperature $\left(26^{\circ} \mathrm{C}\right)$ under a $14 \mathrm{~h}$ light: $10 \mathrm{~h}$ darkness cycle. Genetic males (XY) were obtained by artificial fertilization of eggs from normal females (XX) with sperm from supermales (YY) (Kobayashi et al. 2000). All the animal experiments conformed to the Guide for Care and Use of Laboratory Animals approved by the Committee of Laboratory Animal Experimentation of Southwest University, China.

\section{Isolation and sequence analysis of tilapia pgr CDNA}

Tilapia pgr mRNA sequences, including the open reading frame (ORF) and UTRs, were obtained from a 3-month-old tilapia gonadal transcriptome database (Tao et al. 2013). Gene-specific primers (pgr-ORF-F, pgr-ORF-R) were designed to amplify the full-length pgr cDNA obtained from the testis. RNA isolation and cDNA synthesis were carried out according to the methods reported previously (Zhou et al. 2007). PCR products were ligated into the pGEM-T Easy Vector (Promega) and sequenced at Life Technologies Corporation.

\section{Phylogenetic analysis}

The deduced amino acid sequences of tilapia Pgr and its counterparts in other vertebrates were aligned using ClustalW with default alignment parameters.

Published by Bioscientifica Ltd 
A phylogenetic tree was generated with Mega 5.0 by the neighbor-joining method (Tamura et al. 2007) using tilapia glucocorticoid receptor 1 (XP_003446987.1) as an outgroup. Values on the tree represent the bootstrap scores of 1000 trials, indicating the credibility of each branch. The GenBank accession numbers of the Pgr sequences used in this study are as follows: AAA49013.1, chicken (Gallus gallus); BAA89539.1, Japanese eel-1; BAB85993.1, Japanese eel-2; NP_000917.3, human (Homo sapiens); NP_032855.2, mouse (Mus musculus); BAF91193.1, turtle (Pseudemys nelsoni); AAG42362.1, Xenopus-1 (Xenopus laevis); AAL 55260.1, Xenopus-2; NP_001165515.1, medaka (Oryzias latipes); XP_003968702.1, fugu (Takifugu rubripes); ACF21816.1, cod; NP_001239292.1, salmon; ACQ 90238.1, zebrafish; NP_001192285.1, bovine (Bos taurus); and $\mathrm{KJ} 427809$, tilapia.

\section{In vivo treatment with RU486, DHP, and 11-KT}

In these experiments, $\mathrm{XY}$ fish were divided into six groups: group I, fish treated with RU486 for 2 months; group II, fish treated with RU486 for 5 months; group III, fish treated with RU486 for 3 months; group IV, fish treated with RU486 plus 11-KT for 3 months; group V, fish treated with RU486 plus DHP for 3 months; and group VI, control fish. All the treatments were started from 5 dah in aerated fresh water. Briefly, group I fish were fed daily with a RU486-mixed (500 $\mu \mathrm{g} / \mathrm{g}$; Sigma) commercial diet from
5 dah for 2 months and then fed with a normal diet until sampling. Group II fish were fed with RU486 $(500 \mu \mathrm{g} / \mathrm{g}$ food) for 5 months and sampled immediately. Groups III-V fish were treated separately with RU486 alone, RU486 (500 $\mu \mathrm{g} / \mathrm{g}$ food) plus 11-KT (100 $\mathrm{g} / \mathrm{g}$; Sigma), and RU486 plus DHP (1500 $\mu \mathrm{g} / \mathrm{g}$; Sigma) for 3 months and then fed with a normal commercial diet for another 1 month before sampling. Fish from the same batch fed with a normal commercial diet were used as controls. At 4 months after hatching (mah), gonads from groups III-V and control group fish were sampled and stored for subsequent histological observations, immunohistochemistry (IHC), and real-time PCR analysis. Ten fish of group III were further reared with a normal commercial diet until 9 mah and used for histological observations. A schematic representation of chemical exposure, sampling timing, and purpose is shown in Fig. 1.

\section{Real-time PCR analysis}

The primer sets used for real-time PCR analysis were designed using Primer Express Software (Applied Biosystems) with at least one primer in each set flanking the intron-exon boundary to prevent amplification of the genomic DNA. Liner standard curves were generated with serial tenfold dilutions of each plasmid DNA containing the ORFs of target genes and endogenous reference genes. All real-time PCRs were carried out in an

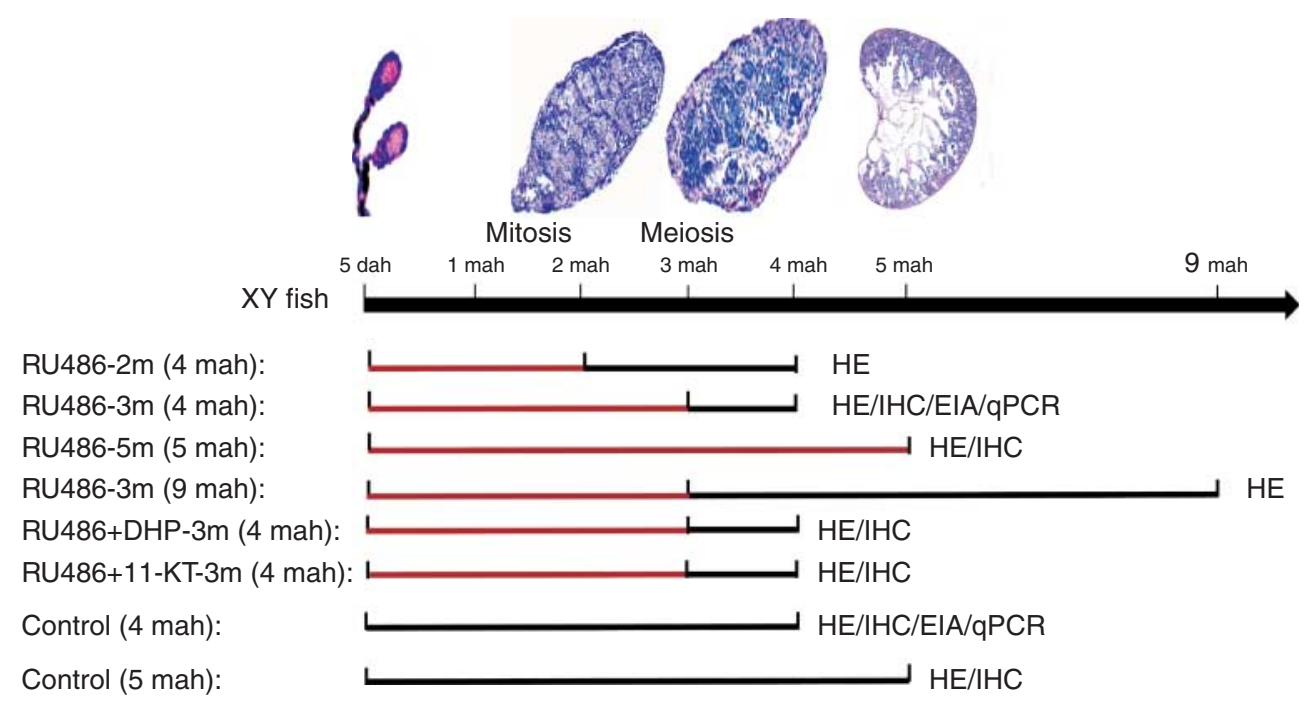

Figure 1

Schematic representation of chemical exposure, sampling timing, and purpose. The lines colored red and black indicate the duration of treatment with a drug-mixed feed and a normal feed, respectively.
The testicular morphology of tilapia at 5 days after hatching (dah), and 2, 3 and 5 months after hatching (mah) is also shown. http://jme.endocrinology-journals.org DOI: 10.1530/JME-13-0300
() 2014 Society for Endocrinology Printed in Great Britain
Published by Bioscientifica Ltd 
ABI-7500 fast real-time PCR machine (Applied Biosystems) in a $20 \mu \mathrm{l}$ reaction with a mixture of $10 \mu \mathrm{l} 2 \times$ SYBR Premix ExTaq (TaKaRa, Dalian, Liaoning, China), $2 \mu$ l of diluted cDNA or PCR-grade water as a negative control, $6 \mu \mathrm{l}$ of PCR-grade water, and $1 \mu \mathrm{l}$ of $10 \mu \mathrm{M}$ gene-specific primer. The PCRs were initiated by denaturation at $95^{\circ} \mathrm{C}$ for $5 \mathrm{~min}$, followed by 40 amplification cycles at $95^{\circ} \mathrm{C}$ for $15 \mathrm{~s}$ and $60^{\circ} \mathrm{C}$ for $30 \mathrm{~s}$ with a final elongation step of $72^{\circ} \mathrm{C}$ for $45 \mathrm{~s}$. Dissociation protocols were used to measure the melting curves. Before normalizing the data, the stability of three internal control genes, ef $1 a$, actb, and gapdh, was analyzed, and the geometric mean of the copy numbers of the three endogenous reference genes was used to normalize the expression of target genes. The relative expression level (RNA abundance) was calculated by dividing the copy numbers of the target gene by the geometric mean of the three reference genes. Data are expressed as means \pm s.E.M. Furthermore, significant differences $(P<0.05)$ in the results were analyzed using Kruskal-Wallis ANOVA with GraphPad Prism 4 Software (GraphPad, San Diego, California, USA).

\section{Ontogenic expression analysis of pgr and sycp3 genes}

For ontogenic expression analysis, three independent samples of gonads were collected from XY fish at 5 dah, 10 dah, 30 dah, 50 dah, 3 mah, and 12 mah. Subsequently, total RNA was extracted using the RNeasy Mini Kit (Qiagen, Düsseldorf, Germany), and cDNA synthesis was performed using the PrimeScript RT Reagent Kit with gDNA Eraser (TaKaRa) according to the manufacturer's instructions. All the real-time PCR and statistical analysis procedures were carried out as described above.

\section{IHC of Pgr expression in the testis of tilapia}

Testes were dissected from 2- and 5-month-old tilapia and fixed in Bouin's solution immediately for IHC. Briefly, tissues were dehydrated for 5 min with 75 , 90, and $100 \%$ ethanol and $100 \%$ xylene, embedded in paraffin, and cut into 5 - $\mu \mathrm{m}$-thick sections. The sections were then deparaffinized by 5 -min washes with $100 \%$ xylene, $100 \%$ ethanol, 95\% ethanol, and 70\% ethanol and twice with PBS. The sections were incubated overnight at $4{ }^{\circ} \mathrm{C}$ with zebrafish Pgr antibodies (1:500 dilution; a generous gift from Professor Yong Zhu, East Carolina University in Greenville) and rinsed with $0.01 \mathrm{M}$ PBS three times for $5 \mathrm{~min} /$ wash. Subsequently, the tissue sections were incubated with a second antibody (goat anti-rabbit $\operatorname{IgG}$ ) conjugated with HRP (Bio-Rad) at 1:2000 for $30 \mathrm{~min}$ and then rinsed with PBS three times for $5 \mathrm{~min} /$ wash. Immunoreactive signals were visualized using diaminobenzidine (Sigma) as the substrate, and the sections were counterstained with hematoxylin. For the negative control, the primary antibody was replaced with normal rabbit serum.

\section{Morphological observations and IHC}

Testes were dissected from fish of the RU486-treated and control groups at different developmental stages and fixed in Bouin's solution for morphological observations by HE staining. Testes from XY fish treated with RU486 for 3 months and sampled at 4 mah or testes from XY fish treated with RU486 for 5 months were fixed for IHC according to the aforementioned protocol. Briefly, the samples were embedded in paraffin and cut into $5-\mu \mathrm{m}$ thick sections. Subsequently, the sections were deparaffnized, hydrated, and treated with a blocking solution (Roche), then incubated independently with the Vasa, Sycp3, Cyp11b2, Dmrt1, and Cyp17a1 polyclonal antibodies (1:1000) overnight at $4{ }^{\circ} \mathrm{C}$, and rinsed with $0.01 \mathrm{M}$ PBS three times for $5 \mathrm{~min} /$ wash. Finally, the sections were incubated with a second antibody and counterstained with hematoxylin. Polyclonal antibodies used for IHC were produced by immunizing the New Zealand white rabbits with each of the purified recombinant proteins generated from the partial coding region of tilapia vasa, sycp 3, cyp11b2, dmrt1, and cyp17a1 genes. Sera were collected after immunizing the rabbits three times and purified by affinity chromatography on Sepharose 4B Fast Flow resin coupled with the respective recombinant protein. In this study, all the images for HE staining and IHC were acquired with a Zeiss Axio Imager Z2 microscope equipped with an AxioCam MRc digital camera.

\section{Examination of the effects of RU486 treatment on gene expression}

To examine the molecular changes induced in the testis by RU486 treatment, real-time PCR analyses were carried out to determine the transcript levels of a series of genes including the specific marker genes of Leydig cells, Sertoli cells, and germ cells. Briefly, testes from three control fish and 12 fish treated with RU486 for 3 months were dissected at 4 mah separately. Subsequently, RNA extraction, cDNA synthesis, and real-time PCR for each gonadal sample were carried out independently to investigate the expression profiles of marker genes for germ cells, Sertoli cells, and Leydig cells as mentioned above. The primer

Published by Bioscientifica Ltd. 
Table 1 Primer sequences for RT-PCR, molecular cloning and real-time PCR

\begin{tabular}{l} 
Primer name \\
\hline pgr-F1 \\
pgr-R1 \\
pgr-F2 \\
pgr-R2 \\
pgr-F3 \\
pgr-R3 \\
pgr-F4 \\
pgr-R4 \\
pgr-ORF-F \\
pgr-ORF-R \\
dazl-Q-F \\
dazl-Q-R \\
piwil1-Q-F \\
piwil1-Q-R \\
dmrt1-Q-F \\
dmrt1-Q-R \\
amh-Q-F \\
amh-Q-R \\
star-Q-F \\
star-Q-R \\
cyp17a1-Q-F \\
cyp17a1-Q-R \\
hsd11b2-F \\
hsd11b2-R \\
sycp3-Q-F \\
sycp3-Q-R \\
ef1a-Q-F \\
ef1a-Q-R \\
actb-Q-F \\
actb-Q-R \\
gapdh-Q-F \\
gapdh-Q-R \\
vasa-Q-F \\
vasa-Q-R \\
gsdf-Q-F \\
gsdf-Q-R \\
pgr-Q-F \\
pgr-Q-R \\
cyp11a1-Q-F \\
cyp11a1-Q-R \\
cyp11b2-Q-F \\
cyp11b2-Q-R \\
gat
\end{tabular}

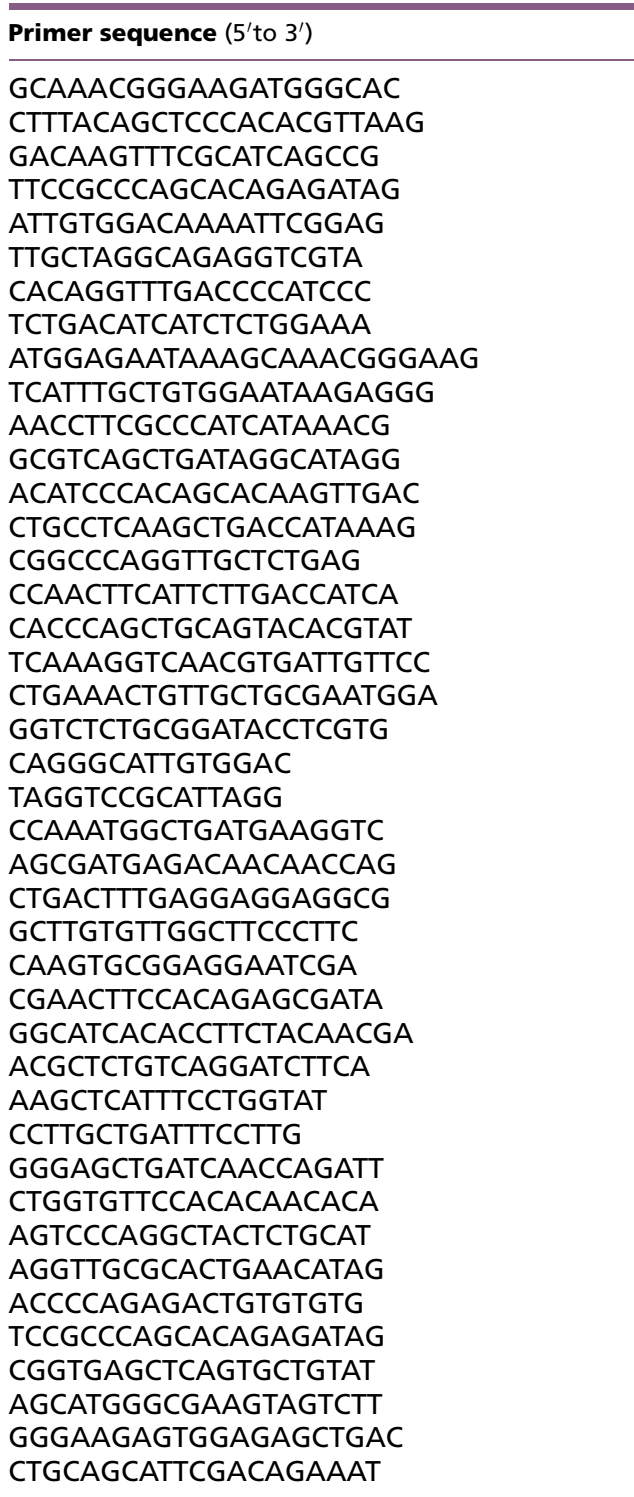

Purpose

Characterization of tilapia pgr by RT-PCR
Real-time PCR sequences used for RT-PCR, molecular cloning, and real-time PCR are listed in Table 1.

\section{Measurement of 11-KT levels by EIA}

For EIA, a minimum of $150 \mu$ of blood was drawn from the caudal vein of XY fish treated with RU486 for 3 months and control fish at 4 mah using a gauge needle and a disposable syringe. Blood samples were centrifuged at $10000 \mathrm{~g}$ for $5 \mathrm{~min}$ at $4{ }^{\circ} \mathrm{C}$, and the supernatant was collected without disturbing the white buffy layer or the blood cells. Finally, 11-KT levels in the serum were measured using the 11-KT EIA Kit according to the manufacturer's instructions (Cayman, Ann Arbor, Michigan, USA).

\section{Results}

Sequences and phylogenetic analysis of tilapia pgr gene

The tilapia pgr gene consisted of 2022 nucleotides and the ORF encoded a protein of 673 amino acids exhibiting similarity (40.5-74.8\%) in the overall sequence across species. Alignment analysis revealed that tilapia Pgr has a typical nuclear receptor structure with a high homology in the DNA-binding domain (DBD; 87.2-96.2\%) and in the ligand-binding domain (LBD; 64.5-85.1\%) with the PGRs of other vertebrates. Importantly, the putative membrane localization motif (FXCXXXXLL) and key residues for progestin binding are quite conserved in the LBD region (Fig. 2). The eight cysteine residues of zinc finger structures

Published by Bioscientifica Ltd. 
Pgr2-Eel

Tilapia

Medaka

Fugu

Cod

Salmon

Zebrafish

Pgr2-Xenopus

Pgr1-Xenopus

Bovine

Human

Mouse

Chicken

Turtle

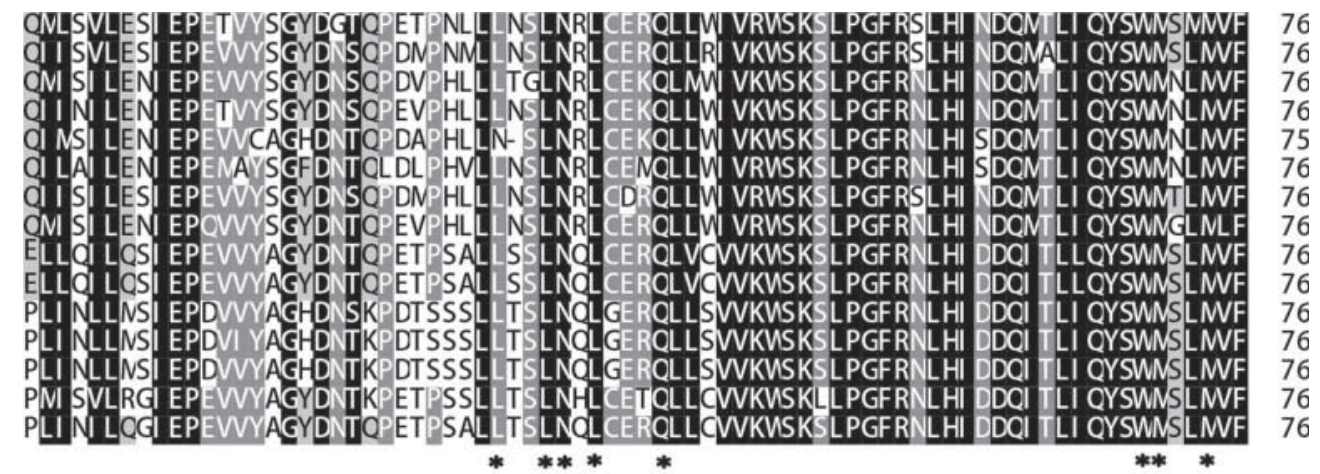

Pgr2-Eel

Pgr1-Eel

Tilapia

Medaka

Fugu

Cod

Salmon

Zebrafish

Pgr2-Xenopus

Pgr1-Xenopus

Bovine

Human

Mouse

Chicken

Turtle

SLGVRSFQNVIREFLYFAPDLI LS EEEKINRINSPI SDLCINAIVQI IPQAFDNLHVIKEEEFLCNKMLLLLNIVPLEGLRS 152

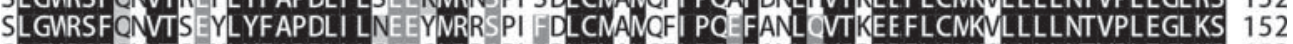
SLGURSFONVTS EYLYFAPDLI LSOEONRRSPI YDLCLAI CFI POEFANL OVSREEFLCNKAII LLNTVPLEGL KS 152 SLGURSFQNVTSEFLYFAPDLI LSQEQNRRSPI YDLCLAI QFI PQEFANL QVTREEFLCNKAI I LLNTVPLEGL KS 152 SLGURSFCNVTSEFLYFAPDLVLSOEENRRSPI SDLCLSI QFVPQEFANL QVSREEFLCNKAI LLLNTVPLEGL KS 151 SLGMRSFKNVTSEFLYFAPDLI LNCDOMROSPI Y YLCLANCFI PQEFANLOVTREEFLCNKAI I LLNTVPLEGLKS 152 SLGVRSFONVTS EYLYFAPDLI LSCDRMRRSPI YDLCLANOFI PQEFTSL OVTKEEFLCNKAI MI LNTVPLEGL KS 152 SLGURTFQNVTPDYLYFAPDLVLSNDQLRRSPI YDLCLANQFVPQEFANL QVTKEEFLCNKALMLLNTVPLEGLKS 152 ALGMRSYCHVSGMLYFAPDLI LNEORMKDSSFYTLCLSMMQLPQEFNKLOVTHEEFLCNKALLLLNTI PLEGL KS 152 ANGURSYCHVSGCMLYFAPDLI LNEORNKDSSFYTLCLSMULL PQ FNKL VT HEE FLCNKALLLLNTI PLEGL KS 152 GLGMRSYKHVSGCMLYFAPDLI LNEORMKES SFYSLCLTMUI PQEFVKL VVSEEFLCNKMLLLLNTI PLEGL RS 152 GLGURSYKHVSGOMLYFAPDLI LNEORMKESSFYSLCLTMUI POFFVKL VSOEEFLCNKMLLLLNTI PLEGLRS 152 GLGMRSYKHVSGOMLYFAPDLI LNEQRNKELSFYSLCLTMMI PQEFVKL VVTHEEFLCNKMLLLLNTI PLEGLRS 152 ANGMRSYKHVSGCMLYFAPDLI LNECRI KESSFYSLCLSMQL POE FVRL QVSOEEFLCNKALLLLNTI PLEGLRS 152 ANGMRSYKHVSGMLYFAPDLI LNECRMKES SFY SLCLSMUA PQEFVKLQVSOEEFLCNKSLLLLNTI PLEGLRS 152

Pgr2-Eel Pgr1-Eel Tilapia Medaka

Fugu

Salmon

Zebrafish

Pgr2-Xenopus Pgr1-Xenopus Bovine

Human

Mouse

Chicken

Turtle

*

*

**
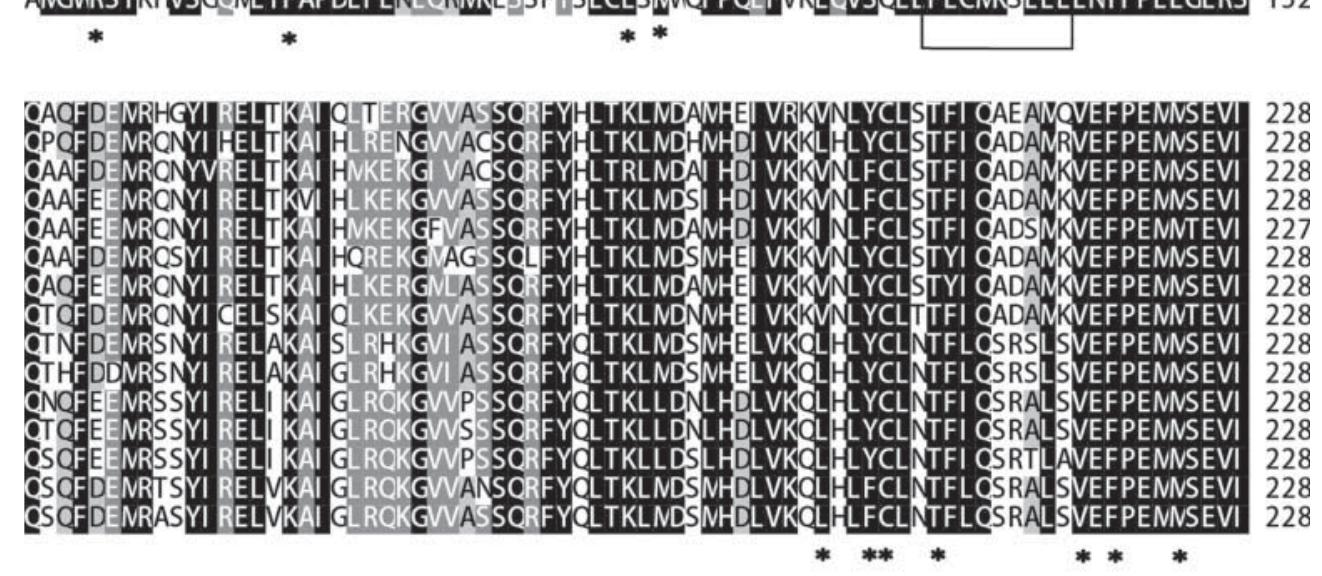

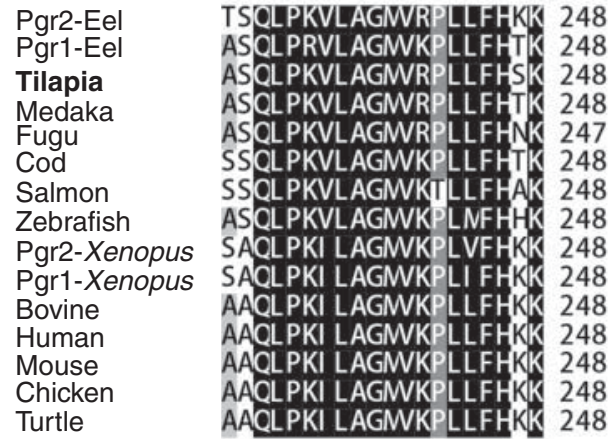

Figure 2

Multiple alignments of amino acid sequences of the ligand-binding domains of vertebrate PGRs. The putative membrane localization motif (FXCXXXXLL) is enclosed by a box. Residues that are important for

http://jme.endocrinology-journals.org DOI: 10.1530/JME-13-0300
C 2014 Society for Endocrinology Printed in Great Britain progestin binding are indicated with asterisks. The Software GeneDoc was used to construct this figure. 


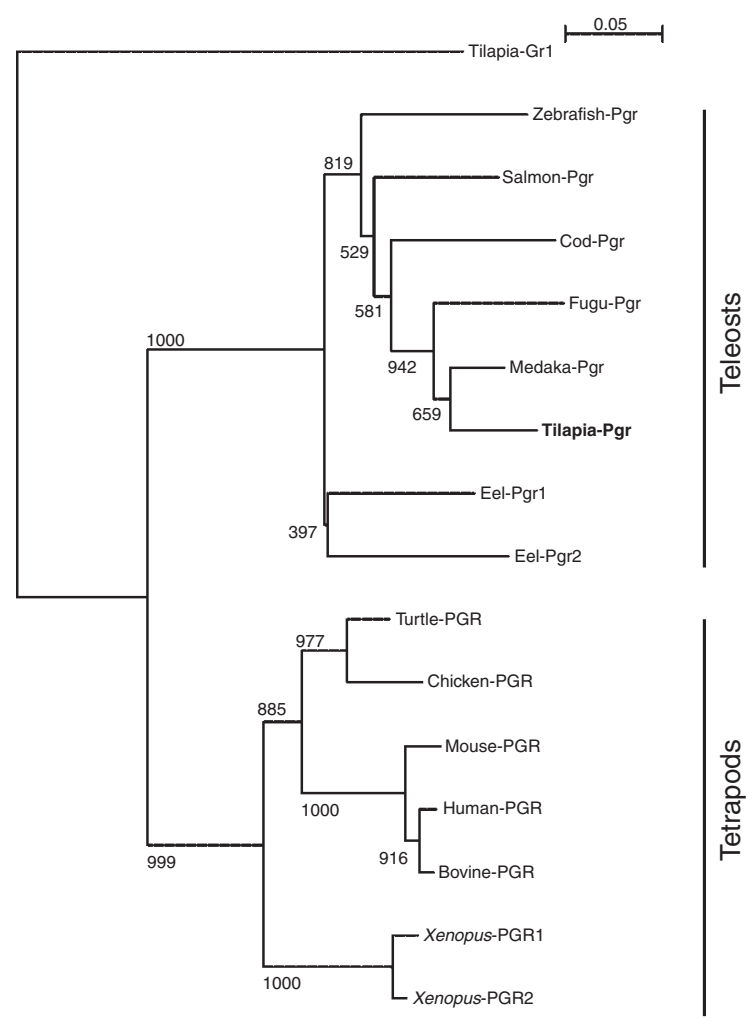

Figure 3

Phylogenetic tree based on conserved ligand-binding domains of vertebrate PGRs with tilapia glucocorticoid receptor 1 (Gr1) as an outgroup. Values on the tree represent bootstrap scores from 1000 trials, indicating the credibility of each branch. Branch lengths are proportional to the number of amino acid changes on the branch (refer to the 'Materials and methods' section for GenBank accession numbers).

and the P box (GSCKV) and the D box (AGRND) sequences are well conserved in the DBD of tilapia Pgr (Supplementary Figure 1, see section on supplementary data at the end of this article). A phylogenetic tree constructed using the LBD sequences revealed that the Pgrs of all fish species clustered into one clade. On the other hand, the PGRs of amphibians, reptiles, birds, and mammals formed a distinct clade (Fig. 3). Our data indicated that the cloned tilapia Pgr was a genuine Pgr.

\section{Ontogenic expression of tilapia pgr and sycp3 genes}

To determine the relationship between $p g r$ and the meiotic marker gene sycp3 (a component of the synaptonemal complex), the abundance of mRNA was measured at different developmental stages of gonads in $\mathrm{XY}$ fish. Morphological observations of the testis of XY fish revealed that the initiation of meiosis occurred only after 60 dah (Fig. 1). Consistently, a rapid increase in sycp3 expression was also observed around 50 dah. Interestingly, real-time
PCR analysis revealed that expression of pgr was also significantly upregulated from $10 \mathrm{dah}$, further increased at 50 dah, and persisted until adulthood (Fig. 4).

\section{Cellular localization of Pgr expression in the testis}

A strong signal of tilapia Pgr could be observed in the Sertoli cells surrounding the early generations of spermatogonia in the testis of 2-month-old XY tilapia (Fig. 5A). Moreover, the expression of Pgr was also detected in the spermatids of 5-month-old XY tilapia (Fig. 5C). However, no positive signals were detected in the testis of 2- and 5-month-old XY fish incubated with normal rabbit serum (Fig. 5B and D).

\section{Effects of RU486, DHP, and 11-KT on spermatogenesis}

Spermatogonia and all phases of spermatogenic cells could be detected in the testis of 4- and 5-month-old XY fish (Fig. 6A, B, O and P). RU486 treatment given for 2 months did not alter the progression of spermatogenesis when checked at 4 mah (Fig. 6C and D). However, RU486 treatment given for 3 months resulted in the depletion of

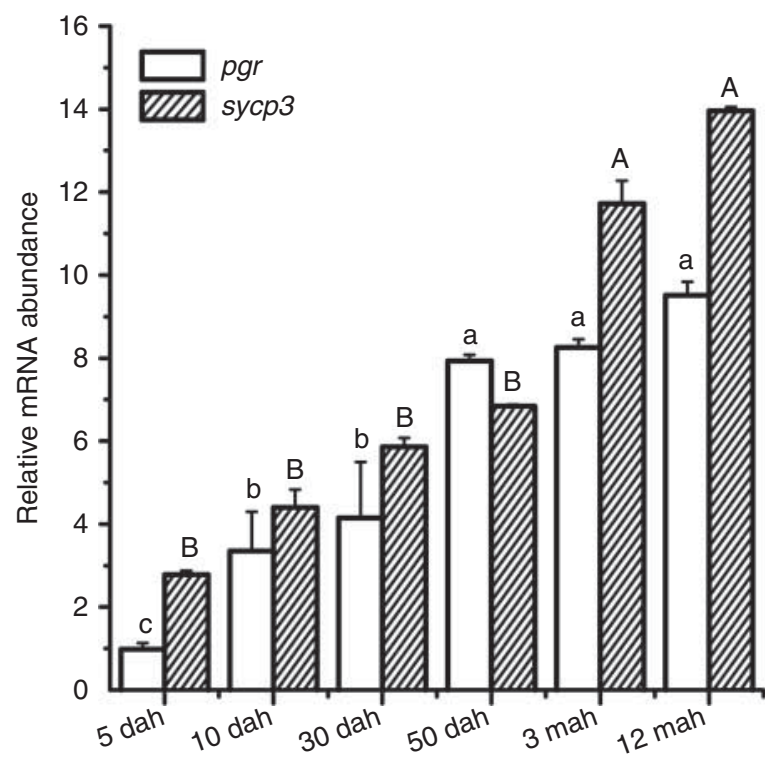

Figure 4

Results of real-time PCR of the mRNA levels of pgr and meiotic marker gene sуср 3 during the different stages of gonadal differentiation at $5,10,30$, and 50 days after hatching (dah) and 3 and 12 months after hatching (mah). Relative mRNA levels are represented as means \pm s.E.M. of three independent samples. The expression level was normalized to the geometric mean of the levels of three internal control genes (gapdh, ef1a, and actb). Different lower-case and capital letters indicate a significant difference in Pgr and sycp3 mRNA levels $(P<0.05)$ respectively. White bar, pgr and striped bar, sycp3.

Published by Bioscientifica Ltd. 


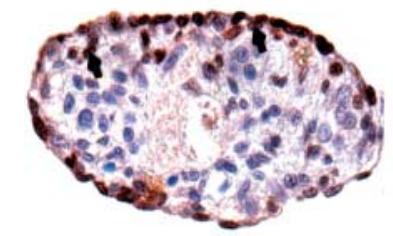

60 dah $X Y$

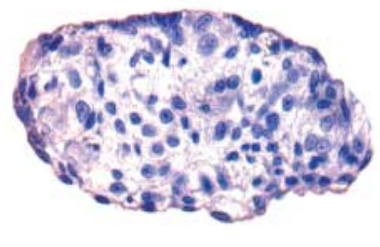

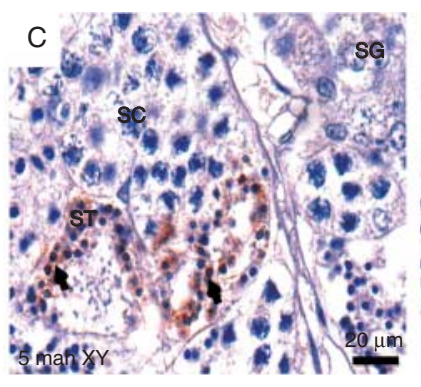

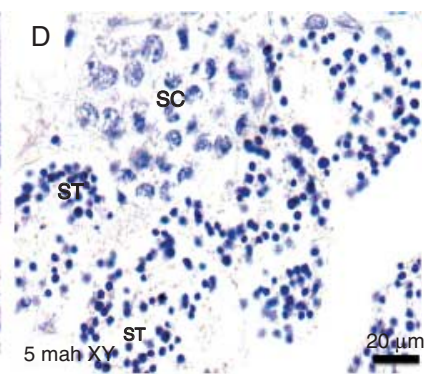

Figure 5

Results of immunohistochemistry of Pgr in the testes of 2-and 5-month-old $X Y$ fish. Positive staining was detected in the Sertoli cells surrounding type A spermatogonia in the testis at 2 months after hatching (mah) (A).

germ cells (Fig. 6G and $\mathrm{H}$ ). In fish subjected to continuous treatment with RU486 for 5 months, only type A spermatogonia, but not type B spermatogonia and laterphase spermatogenic cells, could be detected (Fig. 6M and $\mathrm{N})$. In contrast, in fish subjected to RU486 treatment for 3 months and then fed with a normal diet for the next 6 months, spermatogenesis was restored, as revealed by the large number of spermatids in the testis (Fig. 6E and F).

Surprisingly, simultaneous treatment with DHP and RU486 for 3 months could specifically restore active spermatogenesis and development of all phases of spermatogenic cells (Fig. 6I and J). On the other hand, simultaneous treatment with RU486 and 11-KT failed to initiate spermatogenesis (Fig. 6K and L).

\section{IHC of the testis of the RU486-, DHP-, and 11-KT-treated tilapia}

The testes of 4-month-old XY fish treated with RU486 alone, co-treated with RU486 and DHP, or co-treated with RU486 and 11-KT for 3 months were used for IHC. Consistent with the histological observations, IHC also revealed the absence of Vasa (germ cell marker) and Sycp3 expression, confirming the loss of germ cells in the testis of fish treated with RU486 for 3 months (Fig. 7B and D) in comparison with the 4-month-old control XY tilapia (Fig. 7A and C). On the other hand, no significant changes were observed in the expression of Dmrt1 in Sertoli cells (Fig. 7F) and steroidogenic enzymes involved in 11-KT production in Leydig cells, including Cyp11b2, Cyp17a1, and Star, in the testis of the RU486-treated fish (Fig. 7H, J and L) compared with the control fish (Fig. 7E, G, I and K). Continuous treatment with RU486 for 5 months also failed to alter the expression of genes in Sertoli cells (amh and dmrt1) and that of genes of steroidogenic enzymes involved in 11-KT biosynthesis in Leydig cells (star,
The expression of Pgr was also detected in the cells surrounding spermatids in the testis at 5 mah (C). No immunostaining was detected in the sections incubated with normal rabbit serum as the first antibody ( $B$ and $D$ ).

cyp17a1, and cyp11b2) in the testis (Supplementary Figure 2, see section on supplementary data given at the end of this article).

Intriguingly, a strong Vasa signal, undetectable in the testis of the RU486-treated fish (Fig. 7B), was detected in the spermatogonia and spermatocytes in the testis of the RU486 and DHP-co-treated fish (Fig. 7N), as it was in the testis of the control fish (Fig. 7M). In contrast, Vasa signal was not detected in the testis of the 11-KT and RU486-treated fish (Fig. 7O).

\section{Effects of RU486 treatment on of male-dominant genes and germ line genes}

In accordance with the IHC results, real-time PCR analysis failed to reveal any differences in the gene expression of Sertoli cell markers ( $g s d f$, dmrt1, and $a m h$ ) between the RU486-treated and control fish. In addition, no significant changes were detected in the expression of steroidogenic genes (star, cyp11a1, cyp17a1, cyp11b2, and hsd11b2) involved in 11-KT production in the RU486-treated and control groups, while the expression of cyp17a2, encoding one of the critical steroidogenic enzymes involved in DHP production, was found to be significantly downregulated in the RU486-treated fish. The gene expression of germ cell markers (vasa, dazl, and piwil1) and meiotic maker (sycp3) were found to be significantly decreased in the testis of the RU486-treated fish compared with the control fish (Fig. 8).

\section{Changes in 11-KT levels in the RU486-treated and control tilapia}

11-KT is the major androgen found in the serum of tilapia. To determine whether RU486 treatment for 3 months could affect androgen production, we collected blood

Published by Bioscientifica Ltd 
A

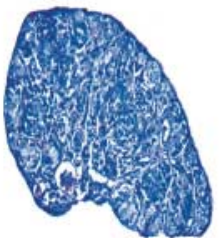

C
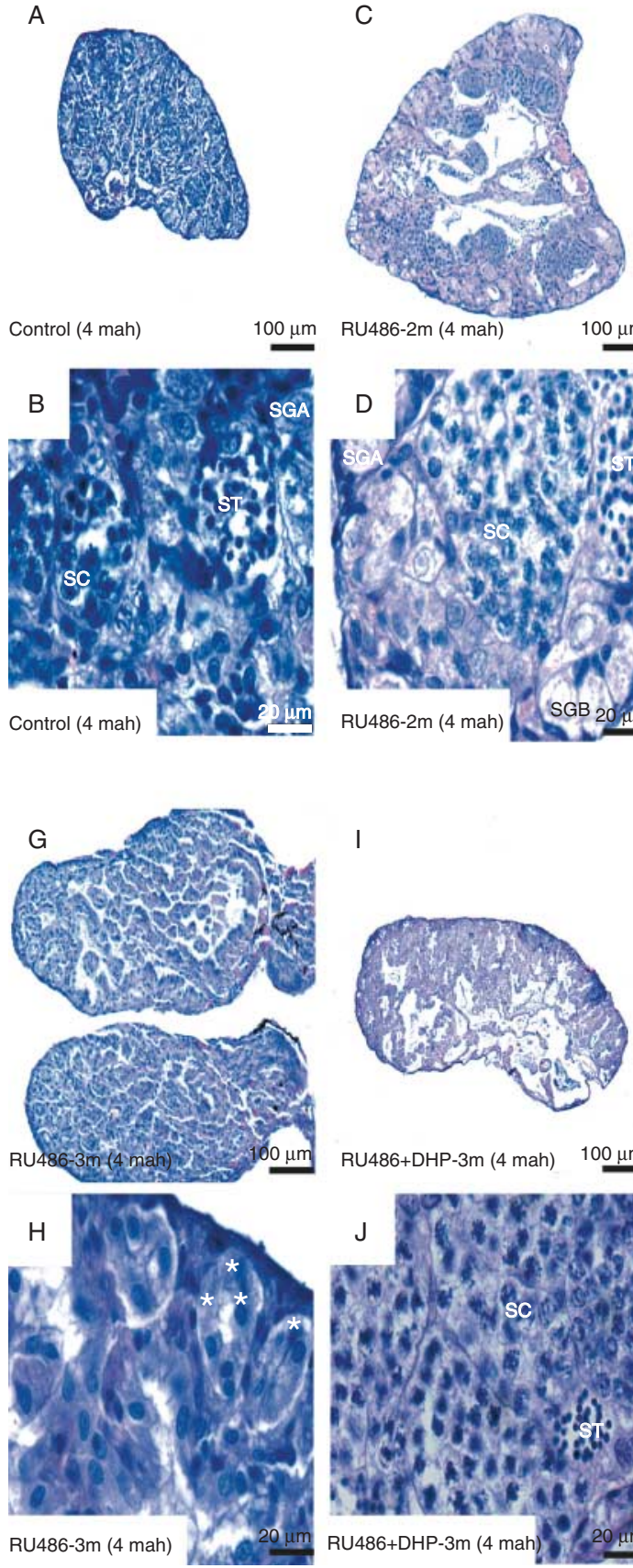

RU486-2m (4 mah)

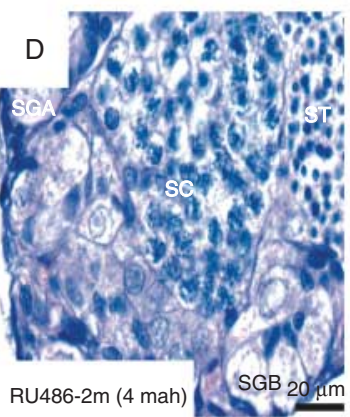

I

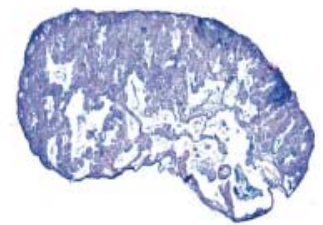

RU486+DHP-3m (4 mah) $100 \mu \mathrm{m}$

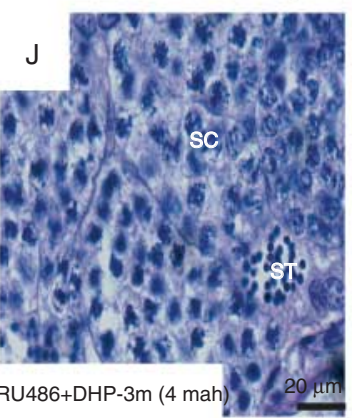

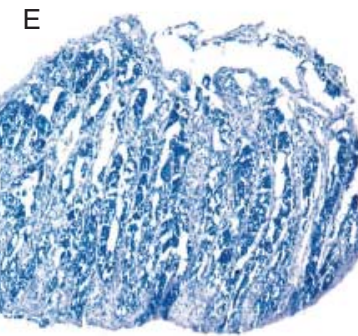

RU486-3m (9 mah)
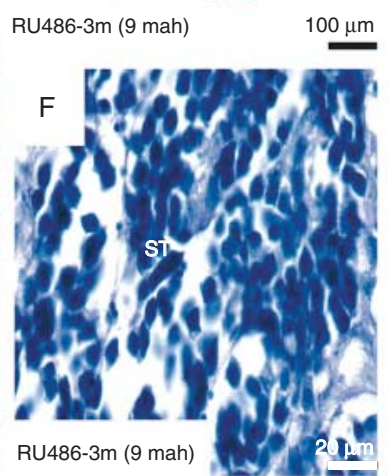

$\mathrm{Bu}$
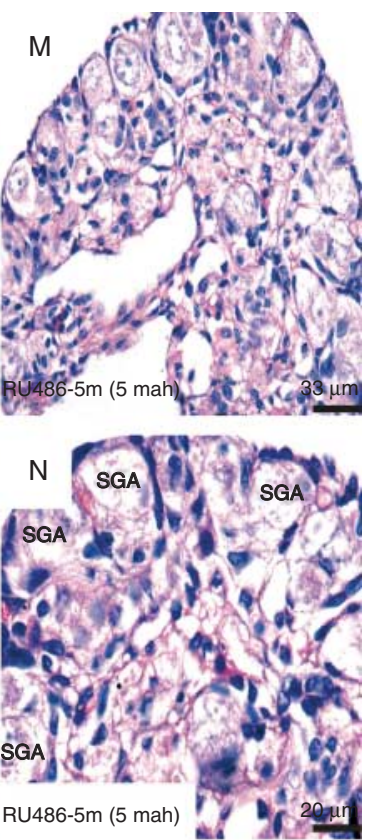

$\mathrm{K}$

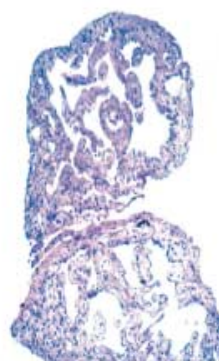

$\mathrm{RU} 486+11-\mathrm{KT}-3 \mathrm{~m}$ (4 mah) $100 \mu \mathrm{m}$

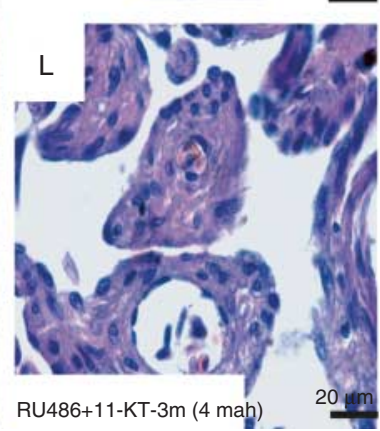

\section{Figure 6}

Morphological observations of the testes of the control fish, fish treated with RU486 alone, fish treated with RU486 plus DHP, and fish treated with RU486 plus 11-KT. Spermatogonia and all phases of spermatogenic cells could be detected in the testis of 4- and 5-month-old $X Y$ fish ( $A, B, O$ and $P$ ). RU486 treatment for 2 months followed by 2 -month feeding with a normal diet did not affect spermatogenesis ( $C$ and D); RU486 treatment for 3 months followed by 1 -month feeding with a normal diet led to the depletion of germ cells. The positions of spermatogonial cysts are indicated with asterisks ( $\mathrm{G}$ and $\mathrm{H}$ ). Spermatogenesis was restored and different stages of spermatogenic cells were observed in the RU486-treated fish (treatment for
3 months followed by feeding with a normal diet) when sampled at 9 mah ( $E$ and F). In the testes of XY tilapia continuously treated with RU486 for 5 months, A type spermatogonia were not affected, while B type spermatogonia and later-phase spermatogenic cells were not observed ( $\mathrm{M}$ and $\mathrm{N}$ ). Simultaneous treatment with RU486 and DHP for 3 months restored spermatogenesis and induced the proliferation and differentiation of all types of germ cells (I and J). However, simultaneous 11-KT treatment for 3 months did not restore spermatogenesis in the testis of the RU486-treated fish ( $K$ and L). SGA, type A spermatogonia; SGB, type B spermatogonia; SC, spermatocytes; ST, spermatid. m, month; mah, months after hatching. 

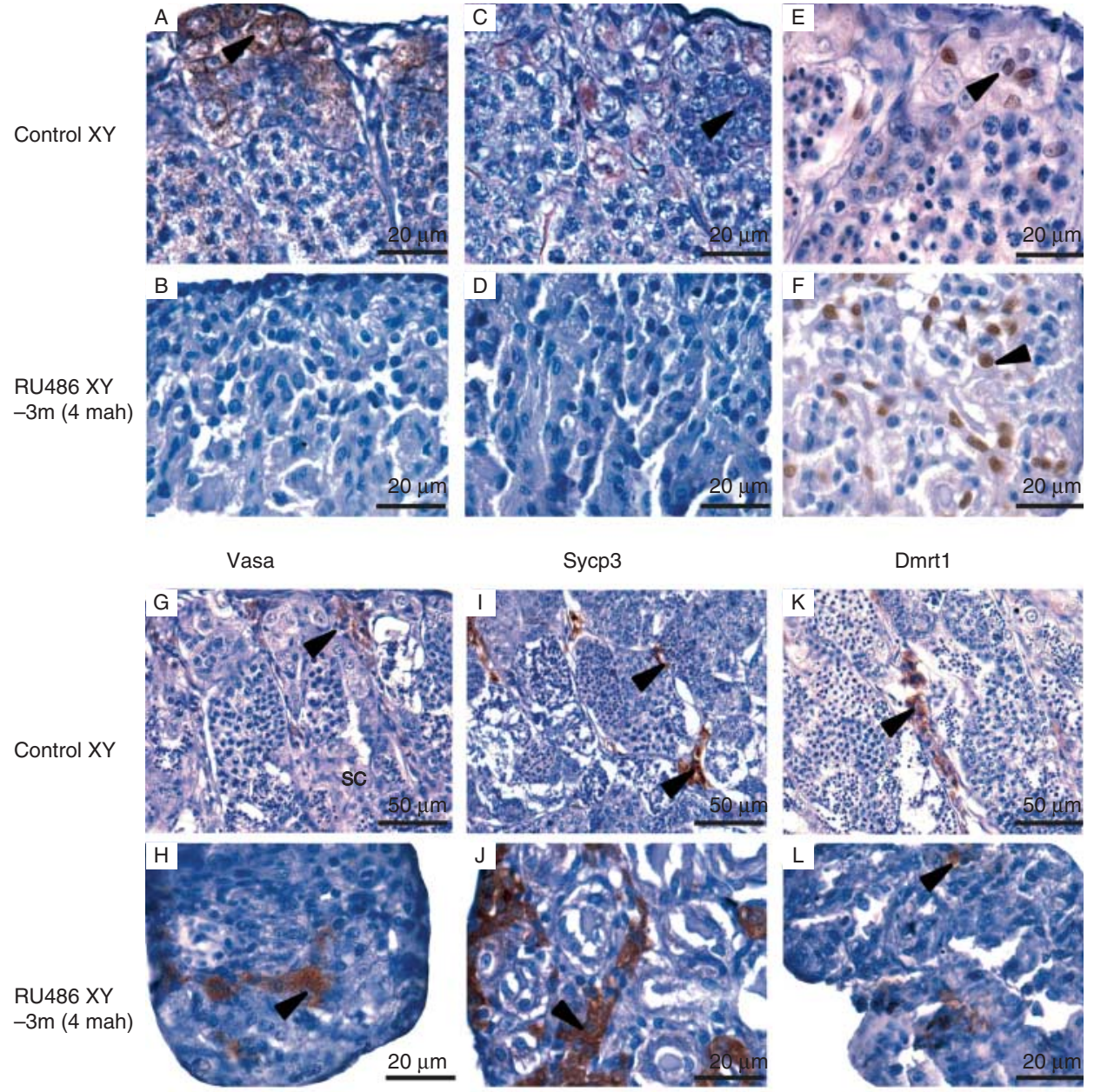

Cyp11b2

Cyp17a1

Star

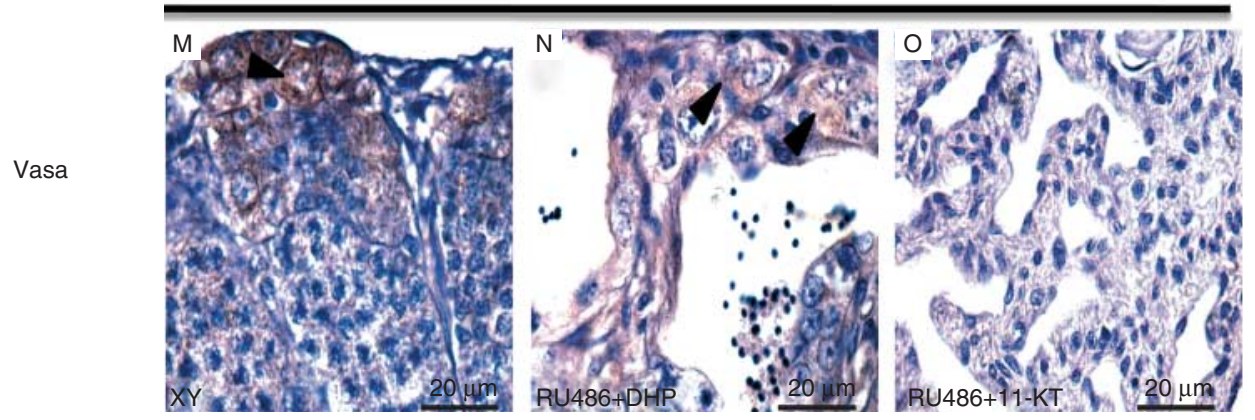

\section{Figure 7}

(A-L) Results of immunohistochemical staining for germ cell, Sertoli cell, and Leydig cell markers in the testis at 4 months after hatching (mah) in the control XY fish and XY fish treated with RU486 for 3 months. Abundant expression of Vasa and Sycp3 was detected in the spermatogonia and spermatocytes in the testis of the control fish ( $A$ and $C$ ), while no positive immunostaining for Vasa (B) and Syср3 (D) was detected in the testis for the RU486-treated fish. Similar to that in the testis of the control fish $(E, G, I$ and $\mathrm{K})$, strong expression of steroidogenic enzymes (Cyp11b2, Cyp17a1, and Star) $(\mathrm{H}, \mathrm{J}$ and $\mathrm{L})$ in Leydig cells and Dmrt1 in Sertoli cells $(\mathrm{F})$ was detected in Printed in Great Britain the testis of the RU486-treated $\mathrm{XY}$ fish. Arrowheads indicate positive immunostaining for each gene. (M-O) Results of immunohistochemical staining for Vasa in the testis at 4 mah in the control fish and $X Y$ fish treated with RU486 plus DHP and RU486 plus 11-KT for 3 months. The expression of Vasa was detected only in the spermatogonia and spermatocytes in the testis of the RU486 plus DHP-treated fish (N) and control fish (M), while it was not detected in the testis of the RU486 plus 11-KT-treated XY fish (O). Arrowheads indicate positive immunostaining for Vasa. 


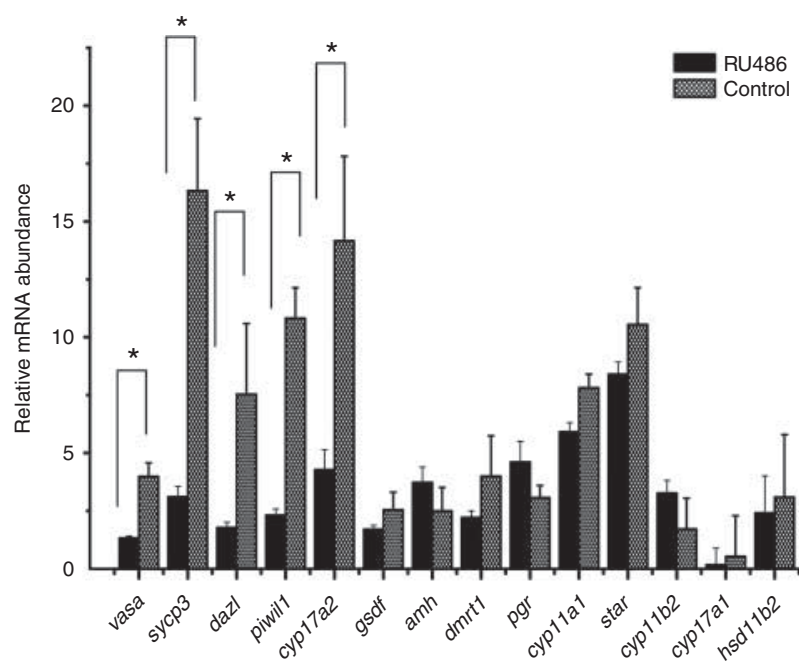

\section{Figure 8}

Results of the expression analysis of marker genes in germ cells, Sertoli cells, and Leydig cells in the testis of the RU486-treated $(n=12)$ and control $(n=3)$ fish by real-time PCR. The transcript levels of germ cell markers (vasa, dazl, piwil1, and sycp3) were significantly downregulated in the testis of the RU486-treated fish, while no difference was detected in the transcript levels of the Sertoli cell markers ( $d m r t 1, a m h$, and $g s d f$ ) and the Leydig cell makers (star, cyp11a1, cyp17a1, and cyp11b2) involved in 11-KT production between the control and RU486-treated fish. However, the expression of cyp17a2, encoding one of the steroidogenic enzymes involved in DHP production, was significantly downregulated in the testis of the RU486treated fish. Relative mRNA levels are represented as the mean \pm s.E.M. of three independent samples for the control fish and 12 samples for the RU486-treated fish. *Indicates a significant difference $(P<0.05)$ between the control and RU486-treated fish.

samples from XY fish treated with RU486 for 3 months and control XY fish at 4 mah and measured the 11-KT levels using EIA. Consistently, no significant difference was observed in serum 11-KT levels between the RU486-treated fish (2.97 ng/ml) and control XY fish (4.15 ng/ml) (Fig. 9).

\section{Discussion}

The Pgr identified in tilapia exhibited a high similarity, especially in the DBD and LBD at the amino acid level, with the nuclear PGRs of other vertebrates, indicating its conserved function across species (Conneely et al. 1987, Schott et al. 1991, Tian et al. 2000, Hanna et al. 2010). The two highly conserved zinc finger motifs, as well as the P box (GSCKV) and D box (AGRND) sequences in the DBD, revealed that tilapia Pgr might be capable of recognizing and binding to its target genes. The alignment of the LBD in the Pgr of tilapia and in the PGRs of other vertebrates confirmed that nearly all the residues important for ligand binding were conserved, indicating its potential role in DHP binding, as demonstrated in other fish species (Chen et al. 2010, 2011, 2012, Hanna et al. 2010). Only one PGR has been identified in vertebrates, except for Japanese eel (Todo et al. 2000, Tsuchiya et al. 2003) and Xenopus, in which two Pgrs have been identified (Bayaa et al. 2000, Tian et al. 2000). In this study, only one Pgr was isolated from tilapia. In silico searches of the tilapia genome database using the UCSC Genome Browser (http:// genome.ucsc.edu) and experimental evidence obtained using RT-PCR with multiple primer sets (pgr-F1-F4; pgr-R1-R4) further support the existence of a single $p g r$ transcript produced from a single locus on LG14 (26733265:26737292) in the genome of tilapia, while the second pgr locus in tilapia might have been lost during evolution, as demonstrated in other fish species (Hanna et al. 2010, Chen et al. 2011).

Plasma DHP levels have been shown to increase with the appearance of meiotic cells in the testis of Japanese huchen, Hucho perryi (Amer et al. 2001), rainbow trout (Scott \& Sumpter 1989), and Atlantic salmon (Chen et al. 2011), indicating that DHP may be functionally involved in the initiation of meiosis, as demonstrated in Japanese eel (Miura et al. 2006). Treatment with DHP for 2 weeks has been shown to revert $\mathrm{E}_{2}$-induced suppression of both spermatogonial cell proliferation and primary spermatocyte differentiation in zebrafish, highlighting the role of DHP in spermatogonial cell proliferation and later stages of spermatogenesis (Chen et al. 2013). Moreover, DHP has been found to have the highest potency to activate $p g r$

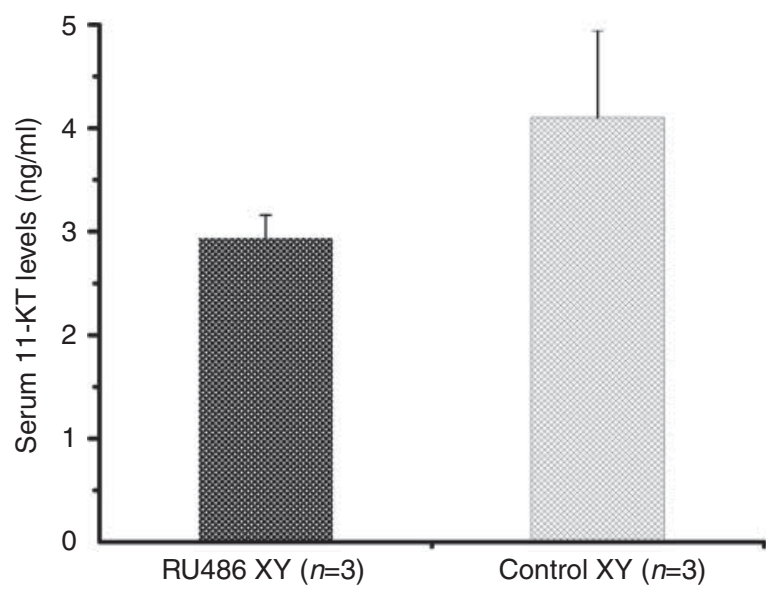

Figure 9

Comparison of serum 11-KT levels between the RU486-treated and control $\mathrm{XY}$ fish. Results are presented as means \pm s.D. Numbers of samples $(n)$ are shown in the figure.

Published by Bioscientifica Ltd. 
transcription in fish in a dose-dependent manner (Chen et al. 2010, 2012, Hanna et al. 2010). In Atlantic cod, testicular pgr expression starts to increase during spermatogonial cell proliferation and reaches maximum levels during the initiation of spermiation (Chen et al. 2012). Therefore, it has been suggested that DHP could stimulate the early stages of spermatogenesis, possibly by upregulating Pgr expression, based on its expression, profile and in vitro experiments (Chen et al. 2010). In this study, we observed significantly elevated and persistent expression of $p g r$ before the onset of spermatogonial cell proliferation and initiation of spermatogenesis, which take place at around 60 dah in XY tilapia (Kobayashi et al. 2000). The expression of Pgr in the Sertoli cells surrounding spermatogonial cells in the testis of 2-month-old XY tilapia also indicated that Pgr might be involved in the induction of spermatogonial cell proliferation and initiation of meiosis, as demonstrated in Japanese eel, zebrafish, and cod (Miura et al. 2006, Chen et al. 2010, 2012). Moreover, the expression of Pgr in cells surrounding spermatids in the testis of 5-month-old XY tilapia indicated its possible role in sperm maturation as high levels of DHP production could be detected during oocyte and sperm maturation in teleosts (Ueda et al. 1985, Nagahama 1997). Even though the levels of DHP were not measured during the early stages of spermatogenesis in tilapia, the transcript levels of cyp17a2, one of the critical steroidogenic enzymes involved in DHP production during oocyte maturation, were found to increase in the Leydig cells from 60 dah in the gonads of XY fish. Therefore, it has been suggested that DHP is possibly synthesized around the time of meiosis initiation during sexual differentiation of the testis of tilapia (Zhou et al. 2007). Taken together, spatiotemporal expression profiles of tilapia pgr indicated that DHP, possibly via Pgr, might be involved in germ cell proliferation and spermatogenesis.

DHP, a fish-specific progestin, is the most potent ligand to bind fish nuclear Pgr, which had been proved using an in vitro system in several fish species including zebrafish, salmon, and cod (Chen et al. 2010, 2012, 2013). In previous research, the antagonism between RU486 and progestin, by competing for binding to Pgr, has been well studied in mammalian species and zebrafish (Leonhardt \& Edwards 2002, Heikinheimo et al. 2003, Chen et al. 2010, Delgado \& Davenport 2012). In this study, morphological observations revealed that RU486 treatment for 3 months resulted in the inhibition of spermatogonial cell proliferation and spermatogenic cell differentiation in XY tilapia. A significant decrease in the gene expression of germ cell markers and a meiotic marker in the testis of the
RU486-treated fish, as revealed by real-time PCR analysis, also indicated the decrease in spermatogonial and spermatogenic cell numbers at 4 mah. The absence of Vasa and Sycp3 protein expression, as determined by IHC, further indicated that RU486 treatment for 3 months led to the depletion of germ cells. Moreover, the presence of A type spermatogonia in the testis of fish continuously treated with RU486 for 5 months further indicated that RU486 affected both the proliferation of spermatogonia and the differentiation of later-phase spermatogenic cells. Therefore, our data support the opinion that DHP might be essential for spermatogonial cell proliferation and later phases of spermatogenesis in tilapia.

It has been reported that progesterone could compete with RU486 for the progesterone receptor and reverse the effects of RU486 in medical abortions (Delgado \& Davenport 2012). Similarly, we found that excessive DHP supplementation could successfully restore spermatogonial cell proliferation and spermatogenesis in the testis of the RU486-treated fish. Moreover, a large number of spermatids could be detected in the testis of 9-month-old XY fish treated with RU486 for 3 months, indicating that spermatogonial cell proliferation and spermatogenesis might be gradually restored in surviving spermatogonial cells by endogenous DHP production after a long-term cessation of RU486 treatment. Additionally, intact spermatogenesis was observed in the testis of 4-monthold XY fish treated with RU486 for 2 months, while depletion of germ cells was observed when the treatment was continued for over 3 months. These findings indicate that RU486 exerted effects only from the time when meiosis was initiated around 70 dah in XY fish. Taken together, our data strongly support the hypothesis that DHP could compete with RU486 for binding to Pgr and reverse the effects of RU486 on spermatogonial cell proliferation and spermatogenesis in tilapia.

Previous reports have revealed that 11-KT might regulate spermatogonial cell proliferation and sperm production (Amer et al. 2001) and DHP accelerates spermatogonial mitosis by promoting 11 -KT production in Japanese eel (Ozaki et al. 2006). In zebrafish, DHP has been found to stimulate the production of 11-KT in a Pgrdependent manner, while RU486 has been found to inhibit the action by antagonizing its binding to Pgr in an organ culture system. In the present study, the occurrence of disrupted spermatogenesis in the RU486treated XY tilapia indicated a Pgr-dependent mechanism. However, we failed to recognize any significant downregulation of the expression of genes encoding steroidogenic enzymes involved in 11-KT production, including

Published by Bioscientifica Ltd. 
star, cyp11a1, cyp17a1, and cyp11b2, in the control and RU486-treated fish. Consistently, RU486 treatment did not affect 11-KT levels in our study. Therefore, our in vivo results reveal a mode of DHP action that is different from that described in previous reports. Similar results have been reported for zebrafish; i.e. there was no change in 11-KT levels when DHP reactivated spermatogenesis in $\mathrm{E}_{2}-$ treated adult XY fish (Chen et al. 2013). Furthermore, DHP treatment successfully restored spermatogenesis in the testis of the RU486-treated fish, while 11-KT could not accomplish this task. It is well accepted that 11-KT is essential for meiosis initiation and spermatogenesis in teleosts (Weltzien et al. 2002, Ozaki et al. 2006, Maugars \& Schmitz 2008, Celino et al. 2009, Zhang et al. 2010). The significant upregulation of $11 \beta$-hydroxylase levels from 50 dah in tilapia also supported this conclusion (Zhang et al. 2010). However, in this study, 11-KT levels remained unchanged in the spermatogenesis-disrupted testis of the RU486-treated fish when compared with the control fish, indicating that 11-KT alone was insufficient to initiate spermatogenesis. DHP treatment from 5 dah to $3 \mathrm{mah}$ could not induce the precocious onset of meiosis in XY tilapia, indicating that DHP alone is also insufficient to activate the initiation of meiosis (data not shown). Taken together, our data indicate that both DHP and 11-KT are indispensable for spermatogenesis, while they might function via different pathways and are regulated independently.

A previous report has revealed that incubation of human granulosa cells with RU486 for $24 \mathrm{~h}$ results in a significant inhibition of progesterone production through a reduction of $3 \beta$-hydroxysteroid dehydrogenase activity (Dimattina et al. 1986). Consistently, our in vivo data revealed that the expression of cyp17a2, encoding one of the critical steroidogenic enzymes involved in DHP production, was significantly downregulated. Therefore, it was suggested that RU486 treatment might also lead to an inhibition of DHP production in fish. However, the mechanism remains to be elucidated.

In conclusion, we identified a nuclear Pgr in the testis of tilapia. It was significantly upregulated at around 50 dah prior to the initiation of meiosis, indicating the possible role of Pgr in the early stages of spermatogenesis. Furthermore, RU486 treatment blocked spermatogenesis, while excessive supplemental or endogenous DHP restored spermatogenesis. Our data indicate that DHP, possibly via Pgr, might be essential for the induction of spermatogonial cell proliferation and spermatogenesis in tilapia.

\section{Supplementary data}

This is linked to the online version of the paper at http://dx.doi.org/10.1530/ JME-13-0300.

\section{Declaration of interest}

The authors declare that there is no conflict of interest that could be perceived as prejudicing the impartiality of the research reported.

\section{Funding}

This study was supported in part by grants for scientific research from the National Natural Science Foundation, of China (31201986 and 31030063); from the Natural Science Foundation Project of CQ CSTC, China (cstc2012jjA80005), from the special fund of Chongqing key laboratory (CSTC); the Specialized Research Fund for the Doctoral Program of Higher Education of China, Ministry of Education, China (20110182120003); from the Fundamental Research Funds for the Central Universities, China (XDJK2010B013), from the Ministry of Education of China, and the National Basic Research Program, China (2012CB723205).

\section{Acknowledgements}

The authors cordially thank Prof. Yong Zhu from East Carolina University, North Carolina, for providing the zebrafish nuclear Pgr antibody.

\section{References}

Amer MA, Miura T, Miura C \& Yamauchi K 2001 Involvement of sex steroid hormones in the early stages of spermatogenesis in Japanese huchen (Hucho perryi). Biology of Reproduction 65 1057-1066. (doi:10.1095/ biolreprod65.4.1057)

Bayaa M, Booth RA, Sheng YL \& Liu XJ 2000 The classical progesterone receptor mediates Xenopus oocyte maturation through a nongenomic mechanism. PNAS 97 12607-12612. (doi:10.1073/pnas.220302597)

Celino FT, Yamaguchi S, Miura C \& Miura T 2009 Arsenic inhibits in vitro spermatogenesis and induces germ cell apoptosis in Japanese eel (Anguilla japonica). Reproduction 138 279-287. (doi:10.1530/REP-090167)

Chen SX, Bogerd J, Garcia-Lopez A, de Jonge H, de Waal PP, Hong WS \& Schulz RW 2010 Molecular cloning and functional characterization of a zebrafish nuclear progesterone receptor. Biology of Reproduction $\mathbf{8 2}$ 171-181. (doi:10.1095/biolreprod.109.077644)

Chen SX, Bogerd J, Andersson E, Almeida FFL, Taranger GL \& Schulz RW 2011 Cloning, pharmacological characterization, and expression analysis of Atlantic salmon (Salmo salar L.) nuclear progesterone receptor. Reproduction 141 491-500. (doi:10.1530/REP-10-0224)

Chen SX, Almeida FF, Andersson E, Taranger GL, Schmidt R, Schulz RW \& Bogerd J 2012 Cloning, pharmacological characterization and expression analysis of Atlantic cod (Gadus morhua, L.) nuclear progesterone receptor. General and Comparative Endocrinology 179 71-77. (doi:10.1016/j.ygcen.2012.07.022)

Chen SX, Bogerd J, Schoonen NE, Martijn J, de Waal PP \& Schulz RW 2013 A progestin $(17 \alpha, 20 \beta$-dihydroxy-4-pregnen-3-one) stimulates early stages of spermatogenesis in zebrafish. General and Comparative Endocrinology 185 1-9. (doi:10.1016/j.ygcen.2013.01.005)

Conneely OM, Dobson ADW, Tsai MJ, Beattie WG, Toft DO, Huckaby CS Zarucki T, Schrader WT \& Omalley BW 1987 Sequence and expression of a functional chicken progesterone receptor. Molecular Endocrinology $\mathbf{1}$ 517-525. (doi:10.1210/mend-1-8-517)

Published by Bioscientifica Ltd. 
Delgado G \& Davenport ML 2012 Progesterone use to reverse the effects of mifepristone. Annals of Pharmacotherapy 46 e36. (doi:10.1345/aph. 1R252)

Depeche J \& Sire O 1982 In vitro metabolism of progesterone and $17 \alpha$-hydroxyprogesterone in the testis of the rainbow trout, Salmo gairdneri Rich., at different stages of spermatogenesis. Reproduction, Nutrition, Development 22 427-438. (doi:10.1051/rnd:19820314)

Dimattina M, Albertson B, Seyler DE, Loriaux DL \& Falk RJ 1986 Effect of the antiprogestin RU486 on progesterone production by cultured human granulosa cells: inhibition of the ovarian 3B-hydroxysteroid dehydrogenase. Contraception 34 199-206. (doi:10.1016/00107824(86)90072-7)

Hanna RN, Daly SC, Pang Y, Anglade I, Kah O, Thomas P \& Zhu Y 2010 Characterization and expression of the nuclear progestin receptor in zebrafish gonads and brain. Biology of Reproduction 82 112-122. (doi:10.1095/biolreprod.109.078527)

Heikinheimo O, Kekkonen R \& Lahteenmaki P 2003 The pharmacokinetics of mifepristone in humans reveal insights into differential mechanisms of antiprogestins action. Contraception 68 421-426. (doi:10.1016/ S0010-7824(03)00077-5)

Kobayashi T, Kajiura-Kobayashi H \& Nagahama Y 2000 Differential expression of vasa homologue gene in the germ cells during oogenesis and spermatogenesis in a teleost fish, tilapia, Oreochromis niloticus. Mechanisms of Development 99 139-142. (doi:10.1016/S09254773(00)00464-0)

Leonhardt SA \& Edwards DP 2002 Mechanism of action of progesterone antagonists. Experimental Biology and Medicine 227 969-980.

Maugars G \& Schmitz M 2008 Expression of gonadotropin and gonadotropin receptor genes during early sexual maturation in male Atlantic salmon parr. Molecular Reproduction and Development 75 403-413. (doi:10.1002/mrd.20767)

Miura T, Yamauchi K, Takahashi H \& Nagahama Y 1992 The role of hormones in the acquisition of sperm motility in salmonid fish. Journal of Experimental Zoology 261 359-363. (doi:10.1002/jez. 1402610316)

Miura T, Higuchi M, Ozaki Y, Ohta T \& Miura C 2006 Progestin is an essential factor for the initiation of the meiosis in spermatogenetic cells of the eel. PNAS 103 7333-7338. (doi:10.1073/pnas.0508419103)

Nagahama Y 1997 17 $\alpha$,20ß-dihydroxy-4-pregnen-3-one, a maturationinducing hormone in fish oocytes: mechanisms of synthesis and action. Steroids 62 190-196. (doi:10.1016/S0039-128X(96)00180-8)

Ozaki Y, Higuchi M, Miura C, Yamaguchi S, Tozawa Y \& Miura T 2006 Roles of 11ß-hydroxysteroid dehydrogenase in fish spermatogenesis. Endocrinology 147 5139-5146. (doi:10.1210/en.2006-0391)

Schott DR, Shyamala G, Schneider W \& Parry G 1991 Molecular cloning, sequence analyses, and expression of complementary DNA encoding murine progesterone receptor. Biochemistry 30 7014-7020. (doi:10.1021/bi00242a029)

Schulz RW, de França LR, Lareyre JJ, Le Gac F, Chiarini-Garcia H, Nobrega RH \& Miura T 2010 Spermatogenesis in fish. General and Comparative Endocrinology 165 390-411. (doi:10.1016/j.ygcen.2009.02.013)

Scott AP \& Sumpter JP 1989 Seasonal variations in testicular germ cell stages and in plasma concentrations of sex steroids in male rainbow trout (Salmo gairdneri) maturing at 2 years old. General and Comparative Endocrinology 73 46-58. (doi:10.1016/0016-6480(89)90054-3)
Scott AP, Sumpter JP \& Stacey N 2010 The role of the maturation-inducing steroid, 17,20ß-dihydroxypregn-4-en-3-one, in male fishes: a review. Journal of Fish Biology 76 183-224. (doi:10.1111/j.1095-8649.2009. 02483.x)

Senthilkumaran B, Sudhakumari CC, Chang XT, Kobayashi T, Oba Y, Guan GJ, Yoshiura Y, Yoshikuni M \& Nagahama Y 2002 Ovarian carbonyl reductase-like 20ß-hydroxysteroid dehydrogenase shows distinct surge in messenger RNA expression during natural and gonadotropininduced meiotic maturation in Nile tilapia. Biology of Reproduction 67 1080-1086. (doi:10.1095/biolreprod67.4.1080)

Tamura K, Dudley J, Nei M \& Kumar S 2007 MEGA4: molecular evolutionary genetics analysis (MEGA) software version 4.0. Molecular Biology and Evolution 24 1596-1599. (doi:10.1093/molbev/msm092)

Tao WJ, Yuan J, Zhou LY, Sun LN, Sun YL, Yang SJ, Li MH, Zeng S, Huang BF \& Wang DH 2013 Characterization of gonadal transcriptomes from Nile tilapia (Oreochromis niloticus) reveals differentially expressed genes. PLOS ONE 8 e63604. (doi:10.1371/journal.pone.0063604)

Tian JD, Kim S, Heilig E \& Ruderman JV 2000 Identification of XPR-1, a progesterone receptor required for Xenopus oocyte activation. PNAS 97 14358-14363. (doi:10.1073/pnas.250492197)

Todo T, Ikeuchi T, Kobayashi T, Kajiura-Kobayashi H, Suzuki K, Yoshikuni M, Yamauchi K \& Nagahama Y 2000 Characterization of a testicular $17 \alpha$, 20ß-dihydroxy-4-pregnen-3-one (a spermiation-inducing steroid in fish) receptor from a teleost, Japanese eel (Anguilla japonica). FEBS Letters $\mathbf{4 6 5}$ 12-17. (doi:10.1016/S0014-5793(99)01714-7)

Tsuchiya M, Inoue K, Matsuda H, Nakamura K, Mizutani T, Miyamoto K \& Minegishi T 2003 Expression of steroidogenic acute regulatory protein (StAR) and LH receptor in MA-10 cells. Life Sciences 73 2855-2863. (doi:10.1016/S0024-3205(03)00698-2)

Tubbs C \& Thomas P 2008 Functional characteristics of membrane progestin receptor $\alpha(\mathrm{mPR} \alpha)$ subtypes: a review with new data showing $\mathrm{mPR} \alpha$ expression in seatrout sperm and its association with sperm motility. Steroids 73 935-941. (doi:10.1016/j.steroids.2007.12.022)

Ueda H, Kambegawa A \& Nagahama Y 1985 Involvement of gonadotrophin and steroid hormones in spermiation in the amago salmon, Oncorhynchus rhodurus, and goldfish, Carassius auratus. General and Comparative Endocrinology 59 24-30. (doi:10.1016/0016-6480 (85)90415-0)

Weltzien FA, Taranger GL, Karlsen O \& Norberg B 2002 Spermatogenesis and related plasma androgen levels in Atlantic halibut (Hippoglossus hippoglossus L.). Comparative Biochemistry and Physiology. Part A, Molecular \& Integrative Physiology 132 567-575. (doi:10.1016/S10956433(02)00092-2)

Zhang WL, Zhou LY, Senthilkumaran B, Huang BF, Sudhakumari CC, Kobayashi T, Nagahama Y \& Wang DS 2010 Molecular cloning of two isoforms of 11ß-hydroxylase and their expressions in the Nile tilapia, Oreochromis niloticus. General and Comparative Endocrinology 165 34-41. (doi:10.1016/j.ygcen.2009.05.018)

Zhou LY, Wang DS, Kobayashi T, Yano A, Paul-Prasanth B, Suzuki A, Sakai F, Sakai F \& Nagahama Y 2007 A novel type of P450c17 lacking the lyase activity is responsible for C21-steroid biosynthesis in the fish ovary and head kidney. Endocrinology 148 4282-4291. (doi:10.1210/en. 2007-0487)

Received in final form 14 April 2014

Accepted 8 May 2014

Accepted Preprint published online 14 May 2014 http://jme.endocrinology-journals.org DOI: 10.1530/JME-13-0300
() 2014 Society for Endocrinology Printed in Great Britain
Published by Bioscientifica Ltd. 